\title{
La física al servei de l’esport
}

Pol Gimeno (pol.gimeno@sarria.epiaedu.cat)*

Xavier Peribañez (xavier.peribanez@sarria.epiaedu.cat)*

Alumnes de $2 n$ de Batxillerat de Escola Pia Sarrià-Calassanç

Julià Hinojosa (julia.hinojosa@escolapia.cat)**

Professor de física de Escola Pia Sarrià-Calassanç

En aquest article s'exposa part del nostre treball de recerca de $2 n$ de batxillerat en el que mostrem com la millora de la tècnica és fonamental per reduir el temps d'una cursa de natació. Per mostrar-ho ens basem en l'estudi cinemàtic d'un nedador abans i després d'entrenar la tècnica. Els resultats obtinquts mitjançant el tractament de vídeos mostra la millora gràficament i de forma indiscutible.

Paraules clau: natació, millora tècnica, física

This study shows a part of our research for 2nd high school in which we show how to improve the technique is essential to reduce the time from a swimming course. To show this we rely on the kinematic of a swimmer before and after training technique. The results obtained by processing video graphically shows improvement undeniably.

Key words: swimming, techical improvement, physics

\section{OBJECTIU}

Intentarem mostrar que millorant la tècnica sense millorar, la nostra condició física, podíem millorar els resultats i els compararem amb els d'un nedador professional. En el treball vam analitzar els quatres estils de la natació però en l'article, per qüestió d'espai, us mostrarem només l'estil de braça. L'objectiu es analitzar i comparar curses de $10 \mathrm{~m}$ d'un amateur amb un professional mitjançant l'estudi de la posició en funció del temps de cadascun a través de vídeos.

\section{MARC TEÒRIC}

Tant la tècnica com les qualitats físiques creixen de manera paral-lela en el procés de formació de l'esportista, però davant d'una tècnica defectuosa, mal adquirida o mal aplicada per molt elevat que sigui l'estat de forma del esportista, fisiològicament parlant, els guanys es veuran limitats si no s'ha fet una millora tècnica. En definitiva, la tècnica és determinant pel rendiment esportiu. El treball de la tècnica esportiva ha d'ocupar entre un $60 \% \mathrm{i}$ un $70 \%$ del temps d'entrenament en principiants, amb un nombre elevat de correccions i molta precisió (Hernández, 2002).

En tots els estils de natació les posicions del cos han de ser el més hidrodinàmiques possibles. Això significa que, quan nedem, el nostre cos ha d'estar en una posició tal que ofereixi la menor resistència possible a l'aigua. El fet que cada dia es vagin millorant les marques mundials dels nedadors s'atribueix més a la disminució de la resistència creada pels nedadors que a l'augment de la propulsió.

Tal i com explica Hernández (2002), en l'estil de braça el cos fluctua aconseguint la posició horitzontal només en determinats moments. En el cicle de moviment complet s'alternen dues posicions fonamentals, una de màxima extensió i una altra de màxima flexió. 
Màxima extensió: Haurà de ser el més hidrodinàmica possible, amb la mínima inclinació del cap als peus. Els braços estaran estesos i dirigits lleugerament cap avall. Els malucs estaran prop de la superfície de l'aigua igual que les cames, juntes, en extensió i amb els peus en flexió plantar. El cap es manté submergit i inclinat cap a endavant (figura 1).

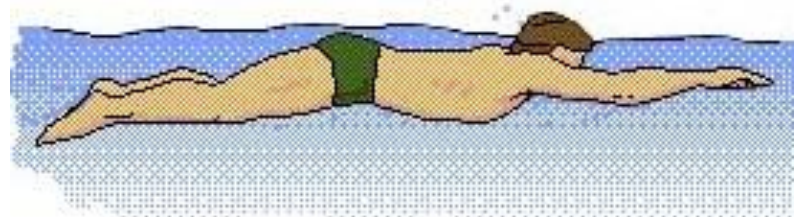

Figura 1. Representació gràfica de la posició de màxima extensió en el cicle de la braça (II.lustració de Microsoft).

Màxima flexió: El tronc està inclinat amb el maluc submergit i les espatlles fora de l'aigua. Els braços estan flexionats per sota i davant del cap iniciant el recobrament. Les cames estan flexionades a nivell del genoll i poc flexionades a nivell del maluc per iniciar la propulsió de les cames. El cap es troba a la màxima altura amb una posició natural (figura 2).

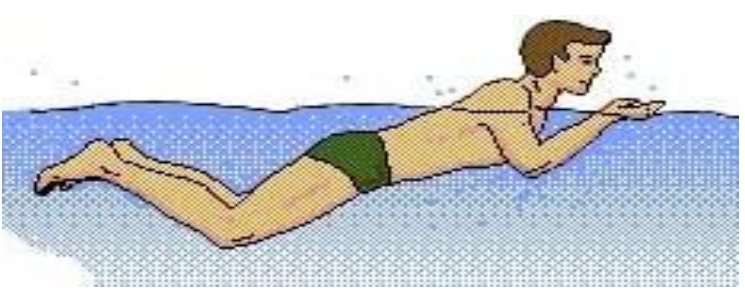

Figura 2. Representació gràfica de la posició de màxima flexió en el cicle de la braça (II.lustració de Microsoft).

D'altra banda l'acció de les cames és de vital importància en l'estil braça. Molt pocs bracistes han aconseguit l'estil sense una bona propulsió de cames. En l'acció de cames de braça hi ha una acció negativa de resistència quan les cames es recuperen a la posició de flexió i per tant es troben flexionades a nivell del genoll, i una de propulsió, que succeeix quan els peus es porten cap a enrere. Per realitzar la puntada, els peus es porten cap als malucs o cap als glutis, flexionant els genolls sense separar-los excessivament. Quan els genolls aconsegueixen la seva màxima flexió, els peus giren cap a fora i es mantenen flexionats. Aquesta acció és molt important per poder realitzar l'acció propulsora que va a conti- nuació, en la qual els peus estan sempre més separats que els genolls formant una "W". En aquesta acció, els peus es mouen com les fulles d'una hèlix, realitzant una acció circular cap a enrere. Al final de la puntada, les plantes dels peus tracten d'ajuntar-se, estenent-se alhora els peus per al lliscament.

\section{METODOLOGIA}

Primerament vam obtenir les gràfiques posició/temps de dos nedadors de diferents nivells: un professional i un amateur (un dels alumnes). Seguidament vam analitzar perquè un anava més ràpid que l'altre mitjançant la gravació dels nedadors durant $10 \mathrm{~m}$. A partir de les gravacions, gràcies a un software, MultiLab (figura 3), vam poder obtenir les gràfiques posició/temps fotograma a fotograma i un cop analitzats els vídeos ens vam adonar que el nedador amateur tenia molt marge de millora tècnica.

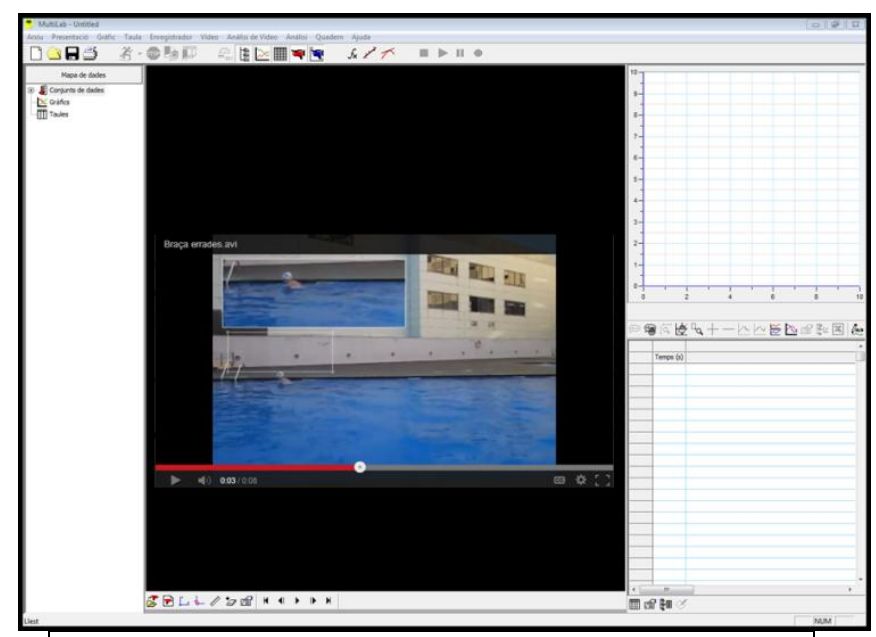

Figura 3. Detall del programa MultiLab.

Després de l'anàlisi de la seva cursa vam dissenyar i portar a terme un programa d'entrenaments tècnics, per millorar la tècnica del nedador amateur. Els entrenaments van ser principalment quatre: peus de braça amb fusta a les mans per millorar la tècnica de peus; peus de braça assegut fora de l'aigua per poder fixar-nos millor en el moviment; nedar braça fixant-se en entrar bé el cap a l'aigua perquè el submergís bé i finalment nedar braça fent dues extensions de cames per cada cicle de braços per treballar la coordinació del moviment.

Una vegada realitzat l'entrenament, durant 81 dies, vam dur a terme la segona gravació 
en la que mostrarem la millora de les seves marques.

\section{RESULTATS}

\section{Pre-entrenaments}

A la figura 4, s'observen els resultats obtinguts després la primera gravació, abans de l'entrenament. Com es pot observar el nedador professional (línia blava, 1,4 $\mathrm{m} / \mathrm{s}$ ) és molt més ràpid que el nedador amateur (línia verda, 0,9 $\mathrm{m} / \mathrm{s}$ ). El nedador professional és gairebé un $36 \%$ més ràpid que l'amateur.

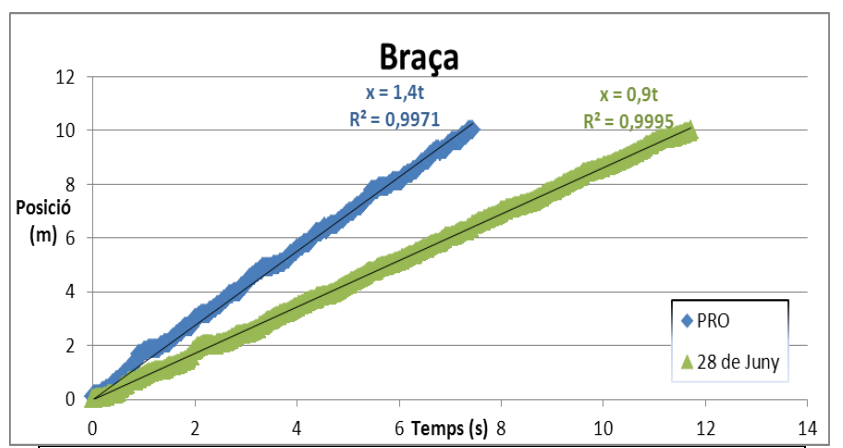

Figura 4. Gràfica de la posició en funció del temps dels diferents nedadors: en blau el nedador professional i en verd l'amateur abans d'haver fet l'entrenament. En el color corresponent s'indica la funció de la línia de tendència i el factor de correlació lineal $\mathrm{R}^{2}$.

A la vista de la figura 4 i analitzant el vídeo [1] amb l'ajut de Blanchart i Miralpeix vam observar que el nedador amateur podia millorar en els següents aspectes:

- En el moviment d'entrada a l'aigua, l'amateur no baixava suficientment el cap per adquirir la posició de mínima resistència a l'aigua, tenint el cos estirat i completament submergit i deixava mig cap fora de l'aigua.

- El moviment de respiració el feia massa lent cosa que provocava que estigués molta estona amb el cap fora de l'aigua i per tant una major fricció amb l'aigua.

- En el moviment de l'impuls, no flexionava suficientment els malucs. Per tant al no recollir les cames en el moviment de respiració, no es produïa un "efecte molla" gaire accentuat i com a conseqüència la propulsió era menor.

\section{Post-entrenaments}

A la figura 5 s'afegeixen els resultats del nedador amateur (en vermell) després de l'entrenament. Es pot observar que ha passat d'anar de $0,9 \mathrm{~m} / \mathrm{s}$ a $1,1 \mathrm{~m} / \mathrm{s}$, cosa que significa una millora d'un $18 \%$. S'ha passat d'una diferència del $36 \%$ (abans de l'entrenament) a una del $21 \%$.

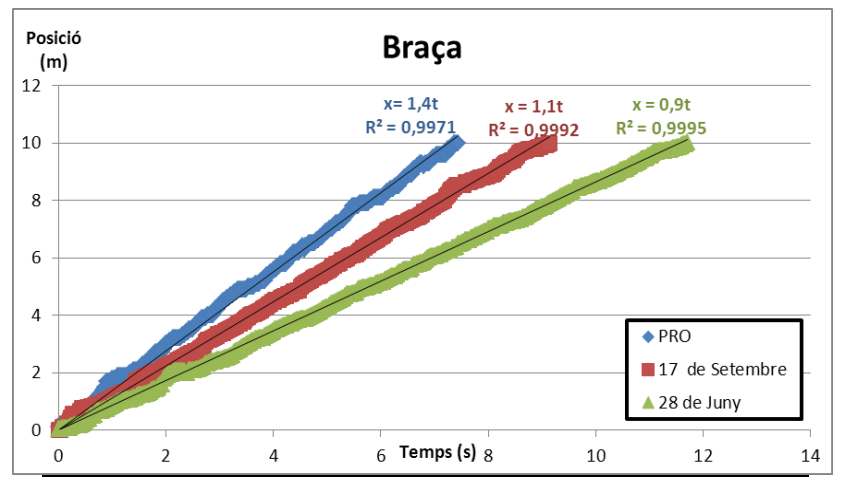

Figura 5. Gràfica de la posició en funció del temps dels diferents nedadors: en blau el nedador professional, en verd l'amateur abans d'haver fet l'entrenament i en vermell l'amateur després d'haver fet l'entrenament. En el color corresponent s'adjunta la funció de la línia de tendència i el factor de correlació lineal $\mathrm{R}^{2}$.

\section{CONCLUSIONS}

Com s'ha mostrat a la figura 5 el nedador amateur ha millorat els seus resultats de forma ostensible, per tant és evident que millorant la tècnica el nedador millora molt els seus resultats, passant en el nostre cas de $0,9 \mathrm{~m} / \mathrm{s}$ a $1,1 \mathrm{~m} / \mathrm{s}$.

En un principi hi ha molts aspectes en els que avançar i per tant es progressa molt ràpidament però cada vegada costa més millorar tècnicament. És aleshores quan s'emfatitza la condició física del nedador. En el treball de recerca també s'estudia la repercussió que té augmentar la distància de la cursa a de 10 a $50 \mathrm{~m}$. Vam poder mostrar que a partir dels 15 $\mathrm{m}$ aproximadament la velocitat del nedador amateur dequeia més significativament, ja que intervenia el factor de la condició física.

\section{AGRAIIMENTS}

Aquest article s'ha pogut fer gràcies al suport de l'Escola Pia de Sarrià-Calassanç. 


\section{REFERÈNCIES}

Blanchart, M. i Miralpeix, X. (nedadors professionals). Comunicació oral.
Hernández, A. (2002). i-Natación

(www.i-natacon.com/articulos/tecnica/i_tecnicas.html)

[1] http://www.youtube.com/watch?v=QFmlluxS6Y\&feature $=$ youtu.be 